\title{
EVALUASI SPO PENGGUNAAN TRACER UNTUK MENGENDALIKAN MISSFILE BERKAS REKAM MEDIS DI BAGIAN FILING UPTD PUSKESMAS I DENPASAR SELATAN
}

\section{SOP EVALUATION OF THE USE OF TRACER TO CONTROL MEDICAL RECORD MISSFILES IN THE FILING SECTION OF UPTD PUSKESMAS I DENPASAR SELATAN}

\author{
Luh Yulia Adiningsih, Deva Eddy Romansyah, I Gusti Ayu Kade Yuli Kanaya \\ Program Studi Diploma IV Manajemen Informasi Kesehatan, Politeknik Kesehatan Kartini Bali
}

\begin{abstract}
ABSTRAK
Manajemen dan mutu pelayanan Puskesmas salah satunya dapat dilihat dari sistem penyimpanan berkas rekam medis di Unit Rekam Medis. Berdasarkan hasil observasi di UPTD Puskesmas I Denpasar Selatan menunjukkan bahwa masih ditemukannya salah letak (missfile) berkas rekam medis saat pengambilan dan pengembalian oleh petugas rekam medis karena petugas rekam medis belum terbiasa menggunakan tracer yang proses pelaksanaannya sejak sebulan yang lalu. Tracer merupakan alat sebagai pengganti berkas rekam medis yang keluar. Penelitian ini bertujuan untuk mengetahui evaluasi penggunaan Standar Prosedur Operasional (SPO) tracer di bagian filing UPTD Puskesmas I Denpasar Selatan. Jenis penelitian ini yaitu penelitian observasional dengan rancangan deskriptif yaitu melakukan deskripsi fenomena yang ditemukan. Subyek dalam penelitian ini adalah tiga orang petugas rekam medis satu orang lulusan S1 Keperawatan dan dua orang lulusan SMA. Obyek dalam penelitian ini adalah SPO tracer di bagian filing. Hasil penelitian menunjukkan bahwa $20 \%$ petugas belum melakukan sesuai dengan SPO tracer yang sudah ada di UPTD Puskesmas I Denpasar Selatan.
\end{abstract}

Kata kunci : Evaluasi, SPO, tracer

\begin{abstract}
One of the management and quality of public health center services can be seen from the medical record file storage system in the Medical Record Unit. Based on observations at the UPTD Puskesmas I South Denpasar, it shows that there are still missfiles medical record files when they are taken and taken by medical record officers because medical records are not used to using a tracker, which has been in implementation since a month ago. Tracer is a tool as a medical record file that comes out. This study aims to see the evaluation of the evaluation of the Tracer Standard Operating Procedure (SOP) in the filing section of the UPTD Puskesmas I, South Denpasar. This type of research is an observational study with a descriptive design that describes the phenomena found. The
\end{abstract}


Bali Medika Jurnal.

Vol 8 No 1, 2021: 27-34

DOI: https://doi.org/10.36376/bmj.v8i1

subjects in this study were three medical record officers, one graduate of Bachelor of Nursing and two high school graduates. The object of this research is the SOP tracer in the filing section. The results showed that $30 \%$ of the officers had not performed according to the SOP to use already in the UPTD Puskesmas I South Denpasar.

Key words : Evaluation, SOP, tracer

\begin{tabular}{ll}
\hline Alamat Korespondensi & : Manajemen Informasi Kesehatan, Politeknik \\
& Kesehatan Kartini Bali \\
Email & : lyauno@yahoo.com \\
\hline
\end{tabular}

\section{PENDAHULUAN}

Puskesmas merupakan salah satu instalasi pelayanan kesehatan sebagai bentuk penguatan pelayanan kesehatan dasar kepada masyarakat. Tracer (outguide) adalah pengganti rekam medis yang akan dikeluarkan dari penyimpanan untuk tujuan apapun, biasanya terbuat dari bahan yang kuat dan berwarna (IFHIMA, 2012). Pentingnya keberadaan tracer mampu meningkatkan efektifitas dan efisiensi dalam menunjukkan dimana rekam medis akan disimpan kembali. Selain itu, tracer juga dapat memastikan bahwa rekam medis setiap kali akan dipindahkan dari penyimpanan untuk tujuan tertentu harus diganti dengan tracer yang menunjukkan dimana rekam medis telah dikirim. Jadi, tracer memungkinkan rekam medis untuk ditelusuri apabila tidak ada di tempat penyimpanan. Hasil penelitian dari Pujilestari (2016) menyebutkan bahwa petugas rekam medis mengeluh tidak adanya tracer membuat mereka kesulitan untuk mengembalikan berkas rekam medis yang keluar dari penyimpanan. Hal ini juga didukung oleh penelitian dari Mardyawati dan Akhmadi (2016) di Puskesmas Bayan Lombok Utara didapatkan bahwa tidak menggunakan tracer di bagian filing mengakibatkan pelaksanaan pengembalian berkas rekam medis yang disimpan tidak sesuai pada tempatnya.

Ketidaktepatan penyimpanan berkas rekam medis (missfile) tentunya akan menghambat pelayanan kesehatan. Penelitian Salim dan Simanjuntak (2018) menyatakan bahwa salah satu faktor penyebab missfile yaitu belum adanya tracer sebagai pengganti berkas rekam medis yang diambil. Terjadinya missfile yang terus-menerus tentunya akan mengurangi mutu pelayanan dari suatu instalasi pelayanan kesehatan. Sehingga penggunaan tracer harus sesuai Standar Prosedur Operasional (SPO) yang telah ditetapkan puskesmas.

Standar Prosedur Operasional (SPO) merupakan alat yang digunakan untuk melaksanakan pekerjaan secara sistematis agar memudahkan petugas dalam melaksnakan pekerjaannya. Selain itu SPO adalah panduan yang digunakan untuk memastikan kegiatan operasional suatu organisasi berjalan dengan lancar (Sailendra, 2015). SPO juga menjadi jalan untuk mencapai suatu tujuan. Hakim, Subanti, dan Tambunan (2011) menyatakan SPO dapat menentukan apakah tujuan dapat dicapai secara efektif, efisien dan ekonomis. Jadi, SPO merupakan sistem yang vital, jika tidak dilaksnakan dengan baik maka manajemen sebuah organisasi kemungkinan besar akan menjadi kacau.

Menurut World Health Organization (2017) menjelaskan bahwa menggunakan petunjuk keluar atau tracer mampu meningkatkan kerja instalasi rekam medis dan pengawasan rekam medis. Pentingnya penggunaan tracer sesuai 
Bali Medika Jurnal.

Vol 8 No 1, 2021: 27-34

DOI: https://doi.org/10.36376/bmj.v8i1

dengan SPO bertujuan untuk memastikan bahwa rekam medis setiap kali akan dikeluarkan dari bagian filing dengan tujuan apapun, harus diganti dengan tracer yang berisi keterangan dimana rekam medis tersebut berada. Hal tersebut berguna untuk menngendalikan missfile dan memudahkan petugas rekam medis ketika mencari atau mengambil berkas rekam medis jika tidak ditempatnya.

Berdasarkan hasil observasi di UPTD Puskesmas I Denpasar Selatan pada studi pendahuluan pada Mei 2020 didapatkan bahwa petugas rekam medis belum mengisi secara lengkap form peminjaman berkas rekam medis yang nantinya sebagai keterangan bahwa rekam medis telah keluar. Hal ini juga didukung dari hasil wawancara mendalam dengan petugas rekam medis, bahwa di UPTD Puskesmas I Denpasar Selatan belum siap menggunakan tracer sesuai SPO karena keterbatasan sumber daya manusia yang hanya berjumlah tiga orang. Selain itu, petugas juga mengatakan sering terjadi missfile berkas rekam medis dikarenakan tidak mengisi form peminjaman rekam medis yang diselipkan pada tracer, sehingga membutuhkan waktu yang lama untuk mencari berkas rekam medis yang salah letak tersebut. Kejadian missfile yang terjadi dapat menyebabkan keterlambatan penanganan pasien untuk mendapatkan pelayanan kesehatan sehingga waktu tunggu pasien menjadi lama, sehingga Puskesmas harus melakukan perbaikan terkait masalah tersebut. Jika terjadi missfile pada bagian filing rekam medis secara berkelanjutan, maka akan berdampak negatif pada fasilitas pelayanan kesehatan tersebut.

Salah satu upaya untuk menghindari terjadinya missfile pada bagian filing rekam medis di UPTD Puskesmas I Denpasar Selatan yaitu dengan meelaksanakan penggunaan tracer sesuai SPO. Jika petugas rekam medis sudah melakukan pekerjaan sesuai dengan SPO penggunaan tracer, maka dapat mengurangi dan mengendalikan kejadian missfile. Berdasarkan hasil pemaparan diatas, tujuan dari penelitian ini yaitu melakukan evaluasi SPO penggunaan tracer untuk mengendalikan missfile berkas rekam medis di bagian filing UPTD Puskesmas I Denpasar Selatan.

\section{METODE PENELITIAN}

Jenis penelitian ini yaitu penelitian observasional dengan rancangan deskriptif yaitu melakukan deskripsi fenomena yang ditemukan. Subyek dalam penelitian ini adalah tiga orang petugas rekam medis satu orang lulusan S1 Keperawatan dan dua orang lulusan SMA. Obyek dalam penelitian ini adalah SPO penggunaan tracer di bagian filing. Lokasi penelitian dilakukan di UPTD Puskesmas I Denpasar Selatan pada Mei 2020. Dasar pertimbangan pengambilan penelitian di Puskesmas ini yaitu karena sudah melakukan survei dan pengambilan data terlebih dahulu. Observasi dilakukan dengan menggunakan lembar SPO tracer rekam medis. Wawancara mendalam dilakukan dengan tiga petugas rekam medis dengan pertanyaan tertutup tentang kualifikasi pendidikan petugas rekam medis, SPO tracer rekam medis dan kejadian missfile di UPTD Puskesmas I Denpasar Selatan. Dasar pertimbangan pengambilan penelitian di Puskesmas ini yaitu karena sudah melakukan survei dan pengambilan data terlebih dahulu. Tempat yang digunakan untuk pengambilan data adalah pada Unit Rekam Medis Rawat Jalan khususnya di bagian Penyimpanan Berkas Rekam Medis (Filing). 


\section{HASIL DAN PEMBAHASAN}

\section{Hasil Penelitian}

\section{Kualifikasi Pendidikan Petugas Rekam Medis}

Kualifikasi petugas rekam medis di UPTD Puskesmas I Denpasar Selatan diketahui terdapat empat petugas rekam medis pada tabel 1 .

Tabel 1

Kualifikasi Pendidikan Petugas Rekam Medis

\begin{tabular}{|c|c|c|c|c|}
\hline \multirow[t]{2}{*}{ No } & \multirow[t]{2}{*}{ Jabatan } & \multicolumn{2}{|c|}{ Pendidikan } & \multirow[t]{2}{*}{ Total } \\
\hline & & $\begin{array}{c}\text { S1 } \\
\text { Keperawatan }\end{array}$ & SMA & \\
\hline 1 & $\begin{array}{l}\text { Koordinator Rekam } \\
\text { Medis }\end{array}$ & 1 & & 1 \\
\hline 2 & Pelaksana & & 2 & 2 \\
\hline & Total Keseluruhan & & & 3 \\
\hline
\end{tabular}

Lulusan SMA sebanyak dua orang dan lulusan S1 Keperawatan sebanyak satu orang. Petugas di bagian pendaftaran sebanyak dua orang dan di bagian filing satu orang. Selain itu, satu petugas pendaftaran merangkap membantu petugas filing. Semua penyimpanan berkas rekam medis dilakukan oleh petugas rekam medis.

Berdasarkan hasil wawancara dijelaskan bahwa dengan rata-rata 200 kunjungan/hari tenaga bagian filing kurang karena petugas merangkap pekerjaan yaitu dibagian kasir dan mendistribusikan berkas.

\section{SPO Tracer Rekam Medis}

UPTD Puskesmas I Denpasar Selatan sudah memiliki Standar Prosedur Operasional (SPO) tentang penggunaan tracer sejak satu bulan lalu. Isi SPO tracer yaitu sebagai berikut.

a. Petugas pendaftaran wajib menuliskan "No. Rekam Medis"

b. Petugas pendaftaran wajib menuliskan "Nama Pasien"

c. Petugas pendaftaran wajib menuliskan "Ruangan Peminjaman"

d. Petugas pendaftaran wajib menuliskan "Tanggal Pinjam"

e. Petugas pendaftaran wajib menuliskan "Tanggal Kembali"

f. Petugas pendaftaran wajib menuliskan "Nama Peminjam"

g. Berkas rekam medis diambil dari rak penyimpanan (filing), digantikan dengan tracer yang telah diisi lengkap

h. Tracer dimasukkan (diletakkan) tepat pada posisi berkas rekam medis yang keluar

i. Tracer diambil dari rak penyimpanan apabila berkas rekam medis yang dipakai sudah kembali pada tempatnya

j. Petugas merapikan susunan rekam medis agar tetap rapi dan sesuai dengan tempatnya

Hasil observasi yang dilakukan terhadap petugas rekam medis UPTD Puskesmas I

Denpasar akan disajikan pada tabel 2. 
Tabel 2

Evaluasi SOP Penggunaan Tracer Rekam Medis

\begin{tabular}{clcc}
\hline No & \multicolumn{1}{c}{ Uraian Prosedur } & \multicolumn{2}{c}{ Implementasi } \\
\cline { 2 - 3 } 1 & $\begin{array}{l}\text { Sudah } \\
\text { Petugas pendaftaran wajib menuliskan } \\
\text { "No. Rekam Medis" }\end{array}$ & $\sqrt{ }$ & \\
\hline 2 & $\begin{array}{l}\text { Petugas pendaftaran wajib menuliskan } \\
\text { "Nama Pasien" }\end{array}$ & $\sqrt{ }$ & \\
\hline 3 & $\begin{array}{l}\text { Petugas pendaftaran wajib menuliskan } \\
\text { "Ruangan Peminjaman" }\end{array}$ & $\sqrt{ }$ & \\
\hline 4 & $\begin{array}{l}\text { Petugas pendaftaran wajib menuliskan } \\
\text { "Tanggal Pinjam" }\end{array}$ & \\
\hline 5 & $\begin{array}{l}\text { Petugas pendaftaran wajib menuliskan } \\
\text { "Tanggal Kembali" }\end{array}$ & \\
\hline 6 & $\begin{array}{l}\text { Petugas pendaftaran wajib menuliskan } \\
\text { "Nama Peminjam" }\end{array}$ & $\sqrt{ }$ \\
\hline 7 & $\begin{array}{l}\text { Berkas rekam medis diambil dari rak } \\
\text { penyimpanan (filing), digantikan dengan } \\
\text { tracer yang telah diisi lengkap }\end{array}$ & $\sqrt{ }$ \\
\hline 8 & $\begin{array}{l}\text { Tracer dimasukkan (diletakkan) tepat pada } \\
\text { posisi berkas rekam medis yang keluar }\end{array}$ & $\sqrt{ }$ \\
\hline 9 & $\begin{array}{l}\text { Tracer diambil dari rak penyimpanan } \\
\text { apabila berkas rekam medis yang dipakai } \\
\text { sudah kembali pada tempatnya }\end{array}$ & $\sqrt{ }$ \\
\hline 10 & $\begin{array}{l}\text { Petugas merapikan susunan rekam medis } \\
\text { agar tetap rapi dan sesuai dengan } \\
\text { tempatnya }\end{array}$ & $\sqrt{c}$ Total \\
\hline
\end{tabular}

Berdasarkan hasil observasi dan dokumentasi di UPTD Puskesmas I Denpasar Selatan 20\% petugas belum melaksanakan SPO dengan efektif. Hal ini terlihat pada form peminjaman rekam medis pada tanggal peminjaman dan tanggal pengembalian tidak terisi. Berdasarkan hasil wawancara dengan petugas rekam medis tentang alasan tidak mengisi bagian tanggal peminjaman dan tanggal kembali yaitu karena petugas mengeluh kekurangan waktu untuk mengingat tanggal dan harus memberikan pelayanan dengan cepat. Petugas rekam medis juga menambahkan jika petugas sering lupa dalam pengisian tanggal peminjaman dan tanggal pengembalian karena membutuhkan waktu berpikir, sedangkan mereka harus melakukan pekerjaaan dengan cepat agar pasien tidak lama menunggu. Selain itu, jumlah petugas rekam medis juga terbatas dan harus merangkap dari pekerjaan yang satu ke pekerjaan lainnya.

\section{Kejadian Missfile di Bagian Filing Rekam Medis}

Berdasarkan hasil wawancara kepada petugas rekam medis mengatakan bahwa kejadian missfile hampir tidak pernah terjadi sejak diterapkan SPO penggunaan tracer rekam medis. Petugas rekam medis juga menjelaskan bahwa 
Bali Medika Jurnal.

Vol 8 No 1, 2021: 27-34

ISSN : 2615-7047

DOI: https://doi.org/10.36376/bmj.v8i1

dengan adanya SPO tracer rekam medis membantu meningkatkan mutu pelayanan sehingga petugas rekam medis tidak membutuhkan waktu yang lama saat pencarian berkas rekam medis yang lama. Contoh kejadian missfile yang ditemui sebelum adanya SPO tracer rekam medis di UPTD Puskesmas I Denpasar Selatan yaitu berkas rekam medis terselip pada rak penyimpanan, rekam medis tidak kembali ke tempat penyimpanan dan kesalahan letak penomeran rekam medis. Petugas rekam medis berharap dengan adanya SPO tracer, kejadian missfile tidak akan pernah terjadi karena akan menurunkan mutu pelayanan dalam penyimpanan berkas rekam medis.

\section{Pembahasan}

Sumber daya manusia memiliki peran yang sangat penting dalam mencapai tujuan suatu organisasi. Dalam hal ini, peran petugas rekam medis dalam melaksanakan Standar Prosedur Operasional (SPO) sangat penting untuk meningkatkan mutu pelayanan kesehatan di puskesmas. Berdasarkan data dari identifikasi man secara kualitatif terdapat tiga orang petugas rekam medis dengan kualifikasi pendidikan yaitu satu orang lulusan S1 Keperawatan dan dua orang lulusan SMA. Implementasi SPO penggunaan tracer akan terlaksana dengan baik jika sumber daya manusianya yaitu petugas tersebut memiliki kualifikasi pendidikan yang sesuai. Profesi perekam medis harus menuasai kompetensinya. Menurut Keputusan Menteri Kesehatan No. 377/MENKES/SK/2007 tentang Standar Profesi Perekam Medis dan Informasi Kesehatan Kompetensi menerangkan bahwa profesi perekam medis yaitu Klasifikasi dan Kodefikasi Penyakit/Tindakan; Aspek Hukum Rekam Medis dan Etika Profesi; Manajemen Rekam Medis dan Informasi Kesehatan; Menjaga dan Meningkatkan Mutu Rekam Medis dan Informasi Kesehatan, Statistik Kesehatan, sedangkan kompetensi pendukung meliputi Kemitraan Kesehatan dan Manajemen Unit Kerja Rekam Medis (Kementerian Kesehatan Republik Indonesia, 2007). Meskipun sudah diberikan pelatihan, namun SDM lulusan SMA tetap harus meningkatkan pendidikannya untuk mendapatkan keahlian atau kompetensi di bidang perekam medis. Wang, Chiang, \& Lee (2014) menjelaskan bahwa pegawai rumah sakit yang bekerja tidak sesuai dengan bidang keilmuannya menyebabkan banyak kesalahan dalam bekerja. Sehingga penanggung jawab pekerjaan tersebut harus orang yang memiliki kompetensi yang sesuai (Mcllveen, 2012).

Berdasarkan hasil observasi dan dokumentasi di UPTD Puskesmas I Denpasar Selatan 20\% petugas belum melaksanakan SPO dengan efektif. Hal ini terlihat pada form peminjaman rekam medis yang tanggal peminjaman dan tanggal pengembalian tidak terisi. Berdasarkan hasil wawancara dengan petugas rekam medis tentang alasan tidak mengisi bagian tanggal peminjaman dan tanggal kembali yaitu karena petugas mengeluh kekurangan waktu untuk mengingat tanggal dan harus memberikan pelayanan dengan cepat. SPO merupakan alat yang mempermudah dan dapat meminimalkan risiko terjadinya kesalahan saat bekerja.

Budihardjo (2014) menjelaskan bahwa SPO adalah suatu perangkat lunak pengatur yang bertujuan mengatur tahapan suatu prosedur kerja dan proses kerja tertentu. SPO penggunaan tracer di UPTD Puskesmas I Denpasar Selatan masih belum sesuai dengan dengan SPO yang telah ditetapkan. Berdasarkan hasil wawancara dengan petugas rekam medis alasan tidak mengisi tanggal peminjaman 
Bali Medika Jurnal.

Vol 8 No 1, 2021: 27-34

DOI: https://doi.org/10.36376/bmj.v8i1

dan tanggal pengembalian karena petugas mengeluh kekurangan waktu untuk mengingat tanggal dan harus memberikan pelayanan dengan cepat.

Missfile merupakan masalah yang cukup sering terjadi di bagian filing rekam medis. Sehingga, petugas rekam medis diharapkan selalu bekerja sesuai SOP agar tidak terjadi missfile. Contoh kejadian missfile yang ditemui di UPTD Puskesmas I Denpasar Selatan yaitu berkas rekam medis terselip pada rak penyimpanan, rekam medis tidak kembali ke tempat penyimpanan dan kesalahan letak penomeran rekam medis. Bagian filing merupakan bagian yang penting dalam penyimpanan berkas rekam medis pasien. Jika pelaksanaan penjajaran berkas rekam medis di bagian filing masih ditemukan salah letak (missfile) dan dokumen tidak ditemukan (hilang), maka akan menghambat proses pengambilan dan pengembalian berkas rekam medis yang disimpan maupun yang dipinjam (Huffman, 1994). Menurut penelitian Rokhman, Budi, dan Nuryati (2015) di Puskesmas Dlingo I Bantul didapatkan bahwa kegiatan penyimpanan berkas rekam medis oleh petugas tidak menggunakan tracer. Hal ini berdampak pada kesalahan letak missfile serta mempersulit pengembalian berkas rekam medis sesuai urutannya. Penelitian Putri (2019) juga menyebutkan bahwa salah satu faktor penyebab missfile yaitu tidak adanya tracer.

Menurut World Health Organization (2017) menjelaskan bahwa menggunakan petunjuk keluar atau tracer mampu meningkatkan kerja instalasi rekam medis dan pengawasan rekam medis. Pentingnya penggunaan tracer sesuai dengan SPO bertujuan untuk memastikan bahwa rekam medis setiap kali akan dikeluarkan dari bagian filing dengan tujuan apapun, harus diganti dengan tracer yang berisi keterangan dimana rekam medis tersebut berada. Hal tersebut berguna untuk mengendalikan missfile dan memudahkan petugas rekam medis ketika mencari atau mengambil berkas rekam medis jika tidak ditempatnya.

\section{SIMPULAN DAN SARAN}

Hasil penelitian menunjukkan bahwa $20 \%$ petugas belum melakukan sesuai dengan SPO penggunaan tracer rekam medis yang sudah diterapkan di UPTD Puskesmas I Denpasar Selatan. Selain itu, petugas rekam medis menyatakan bahwa alasan tidak mengisi bagian tanggal peminjaman dan tanggal kembali yaitu karena petugas mengeluh kekurangan waktu untuk mengingat tanggal dan harus memberikan pelayanan dengan cepat. Diharapkan pihak Puskesmas melakukan kegiatan monitoring dan evaluasi rutin secara berkala dan melakukan brainstorming kembali terkait dengan isi untuk menyesuaikan SPO tracer di Unit Rekam Medis UPTD Puskesmas I Denpasar Selatan agar petugas bekerja sesuai dengan SPO yang berlaku.

Keterbatasan dari penelitian ini adalah hanya melakukan evaluasi terkait SPO tracer rekam medis saja

\section{UCAPAN TERIMA KASIH}

Ucapan terima kasih peneliti sampaikan kepada Direktur Politeknik Kesehatan Kartini Bali, Kepala UPTD Puskesmas I Denpasar Selatan dan petugas rekam 
Bali Medika Jurnal.

Vol 8 No 1, 2021: 27-34

ISSN : 2615-7047

DOI: https://doi.org/10.36376/bmj.v8i1

medis UPTD Puskesmas I Denpasar Selatan yang telah memberikan saran dalam pelaksanaan penelitian ini.

\section{DAFTAR PUSTAKA}

Budihardjo, M. (2014). Panduan Praktis Menyusun SOP. Jakarta: Raih Asa Sukses.

Hakim, A. R., Subanti, S., \& Tambunan, M. (2011). Economic valuation of nature-based tourism object in Rawapening, Indonesia: An application of travel cost and contingent valuation method. Journal of Sustainable Development, 4(2), 91.

Huffman, E. K. (1994). Health Information Management. Illinois: Physician Record Company.

IFHIMA. (2012). Education Modul 3: Record Identification System, Filing and Retention of Health Records. Retrieved from ifhima.org website: https://ifhima.org/learningcenter/

Kementerian Kesehatan Republik Indonesia. Keputusan Menteri Kesehatan nomor 377/MENKES/SK/2007 tentang Standar Profesi Perekam Medis dan Informasi Kesehatan. , (2007). Indonesia.

Mardyawati, E., \& Akhmadi. (2016). Pelaksanaan Sistem Penyimpanan Rekam Medis Family Folder di Puskesmas Bayan Lombok Utara. Jurnal Kesehatan Vokasional, 1(1). https://doi.org/https://doi.org/10.22146/jkesvo.27474

Mcllveen, P. (2012). A Longitudinal Study of The Experience of A Career Development Program For Rural School Students. Career Education and Higher Education, 3(1), $11-14$.

Pujilestari, A. (2016). Pelaksanaan Penyimpanan Berkas Rekam Medis Berdasarkan Unsur Manajemen 5M di RSKIA Permata Bunda Yogyakarta. Universitas Muhammadiyah Surakarta.

Putri, R. R. (2019). Pengaruh Employee Engagement, Organization Citizenship Behavior (OCB) dan Job Satisfaction terhadap Kinerja Karyawan pada PT. Multi Trading Pratama Group Padang. Universitas Putra Indonesia "YPTK" Padang.

Rokhman, N., Budi, S. C., \& Nuryati. (2015). Optimalisasi Sistem Informasi Puskesmas pada Layanan Kesehatan di Puskesmas Dlingo 1 Kabupaten Bantul Yogyakarta. Indonesian Journal of Community Engagement, 1(1), 133-142.

Sailendra, A. (2015). Langkah-Langkah Praktis Membuat SOP. Yogyakarta: Trans Idea Publishing.

Salim, G., \& Simanjuntak, R. F. (2018). Introduksi dan Penerapan Sistem Program Coastal Clean-Up. Jurnal Pengabdian Masyarakat Borneo (JPMB), 2(1), 39-43.

Wang, Y., Chiang, M., \& Lee, Y. (2014). The Relationships Amongst The Intern Anxiety, Internship Outcomes, And Career Commitment Of Hospitality College Students. Journal of Hospitality, Leisure, Sport and Tourism Education, 15(4), 86-93.

World Health Organization. (2017). Communicating Risk In Public Health Emergencies: A WHO Guideline For Emergency Risk Communication (ERC) Policy and Practice. Switzerland: World Health Organization. 